\title{
Do Cyber Victimization and Traditional Victimization Form Separate Factors? Evidence from a Preliminary Study
}

\author{
Anthony C. Betancourt
}

\begin{abstract}
Few published studies measure electronic (cyber) bullying in conjunction with traditional (i.e., verbal, physical, and relational) forms of bullying, with even fewer using multiple items to measure the constructs. These two shortcomings have resulted in decades of inconsistent findings, uncertainty amongst experts about the structure of bullying, and no universally accepted measures to examine it. This study addresses these concerns by developing a new measure of victimization and examining its construct validity in a sample of 399 ninth-grade students. Exploratory Factor Analysis provides strong evidence that victimization is indeed multifaceted with cyber victimization emerging as a separate factor, distinct from school-based forms. Although, physical and verbal victimization items cross-loaded to form a single factor (labeled direct victimization), relational victimization emerged as a separate factor, distinct from cyber and direct victimization. Implications and limitations of these findings are discussed, along with how continued development of such measures may aid educational psychologists who work with victimized students regularly.
\end{abstract}

Index Terms-Bullying, cyber bullying, direct bullying, relational bullying, victimization, construct validity.

\section{INTRODUCTION}

Bullying is defined as repeated, intentional harmful acts, in which a power imbalance exists between the "bully" who commits the harm and the "victim" on the receiving end [1]. Whereas, bullying refers to the overall phenomenon containing both a "bully" and "victim", this paper refers to the act of being bullied as victimization. Both terms are often used interchangeably in the research [2].

\section{A. Types of Victimization}

The most commonly accepted delineation of victimization behavior is Olweus' [1] distinction between physical, verbal, and relational victimization. Physical victimization occurs when one or more individuals physically attack a peer (e.g., hitting or pushing the victim). Physical victimization is the most observable out of all the bullying forms and garners the most attention, particularly given the heightened concern about violence [3]. Fortunately, the proportion of students who use and experience physical aggression, declines with

Manuscript received August 29, 2014; revised November 16, 2014. Al statements expressed in this manuscript are the author's and do not reflect the official opinions or policies of the author's host affiliation. Correspondence concerning this article should be addressed to Anthony C. Betancourt, Department of Educational Psychology, CUNY Graduate Center, 365 E. Fifth Avenue, New York, NY, 10015, USA.

Anthony C. Betancourt is with the City University of New York, USA (e-mail: abetancourt@gc.cuny.edu). age [2], [3].

Verbal victimization involves vocal insults, taunts, or threats of physical violence. In this form, the bully uses his/her advantage of power to throw a verbal assault of damaging comments or threats designed to exploit the various weaknesses of their target, without any fear of reprisal. With each disparaging remark, the power relations become more consolidated. Although viewed as different types of bullying by most educational researchers [1], physical and verbal victimization tend to consist of direct displays of aggression and have often been jointly considered as direct forms of victimization [4], [5].

Meanwhile, relational victimization involves behaviors such as social exclusion, rumor spreading, or with-holding friendship that are designed to damage the victim's peer-relationships through purposeful manipulations of their social networks [3], [4], [6]. Relational victimization is more strongly related to emotional distress than is physical victimization [2] and has been found to be uniquely predictive of social and psychological maladjustment as well as depression in adulthood [7], [8]. Victims of bullying have indicated that social exclusion was the worst form of bullying [2]; however, teachers tend to treat relational bullying as the least serious form [2], [3].

Finally, the recent explosion in the availability of electronic communication technologies has provided students with a new medium to bully [2], [9]. This form of bullying, known in the research as cyber bullying, includes bullying through e-mail, instant messaging, in a chat room, on a website, or through digital messages or images sent to one's phone [2], [10], [11]. As more and more youth utilize the Internet, concern about the consequences of Internet harassment for students is growing. Recent evidence is mounting that online harassment is associated with concurrent psychosocial problems [12], [13] and almost two in five harassed youth (39\%) report emotional distress as a result of the experience [13].

\section{B. Prevalence of Bullying and Gender Differences}

Recent studies, find that around $25.9 \%$ of students experience traditional bullying and $15 \%$ of students experience cyber-bullying, but the vast majority of students do not experience either form of victimization [2], [4]. In terms of gender differences, a review by Thomas et al. [2] found that most studies show that boys are significantly more likely to engage in and be victims of physical bullying. However when it comes to gender differences between verbal, relational, and cyber bullying, the results are mixed. Some find no difference among the three, while others have found 
that girls are more likely to experience and engage in relational and cyber bullying [2,] [4], [14].

\section{Measurement of Bullying}

The majority of bullying studies utilize self-report methodology [2], [4], [5]. These studies use items that cover bullying (e.g., "have you been socially excluded"; "have you been sent harassing text messages from a bully") and correlate them with desired outcomes (e.g., life satisfaction, depression, coping, etc.). Often, such items are ranked on a Likert scale (e.g., "never", "sometimes", "often", "all the time") to provide information on frequency of the behavior. In addition to being intuitive and cost-effective to initiate, studies have shown this approach to be both valid and reliable [2], [4], [5], [9], [15], [16].

Unfortunately, in recent years, researchers have brought to light two significant shortcomings in the bullying literature. First and most apparent is the lack of studies that simultaneously measure cyber and traditional forms of bullying [1], [2], [10], [11]. Second, many studies employ a single-item approach to measure bullying forms (i.e., one item used to represent a whole bullying construct and its relationship to outcomes) [2], [10], 11]. And while there are certainly instances where it is appropriate to use a single item approach (e.g., have you been suspended from school: yes/no), it is a fundamental psychometric principle that multiple items are needed to truly capture complex social phenomena such as bullying and victimization [10], [11].

\section{Purpose of Study}

These shortcomings have led to years of inconsistent findings and no universally accepted measure of victimization [2], [4], [9], [10]. This study attempts to address some of these gaps by developing a new measure of victimization and examining its construct validity in a sample of $9^{\text {th }}$ grade students. There are two primary aims of this study. The first is to determine the dimensionality of victimization, by using multiple items to cover behaviors indicative of cyber, verbal, physical, and relational victimization. In doing so, it is expected that cyber, physical, verbal, and relational victimization will emerge as separate constructs, by way of factor analysis [6]. Second, this study will establish the relative frequency of the different factors of victimization, with the expectation that electronic victimization will be less frequent than the other forms of victimization, replicating work by [2], [4], [17].

\section{MethodOLOGY}

\section{A. Participants}

This sample consists of 399 ninth-graders from a large public high school in New Jersey, USA (184 females, 13 students who did not report their sex). The sample was ethnically diverse, comprising 50\% White, $21 \%$ African-American, 4\% Asian-American, and 12\% Hispanic (with 13\% "other" or declining to answer).

\section{B. Measures}

1) Multidimensional victimization questionnaire $(M V Q)$

Students rated how often they had experienced 28 instances of being victimized (e.g., "Told mean jokes about you") on a 6-point scale, from "Never" (1) to "Often (About 1-2 Times a Day)" (6). Items covered the four content domains of physical, verbal, relational, and electronic victimization (see Table 1 and Table 2 for example items and reliability information).

\section{Procedure}

All 627 ninth-grade students at the school were asked to participate in the study, with parental consent obtained for 541 students $(86 \%)$. Students completed a paper-and-pencil battery during class time, in groups of about 15 (399 students completed all of the items of the victimization scale and were included in the final sample reported here). The battery consisted of the victimization questionnaire listed above, as well as several assessments not relevant to this investigation. All tests and protocols were approved under the administering research institutions' human ethics review committee and fairness review processes.

\section{RESULTS}

\section{A. Exploratory Factor Analysis (EFA) of Victimization Items}

Parallel analysis was conducted for the 28 victimization items in order to determine the number of factors to retain for the EFA [18]. Parallel analysis compares the observed plot of eigenvalues with an eigenvalue plot generated from random data with the same sample size and number of variables. Three observed eigenvalues were greater than the 95th percentile of the randomly-generated eigenvalues, indicating a three-factor solution. Subsequently, an EFA was conducted using Maximum Likelihood with Oblimin Rotation. After removing items that did not load saliently (>.30), or cross-loaded saliently on one or more factors, a three-factor solution with 23 items was obtained (see Table I). Items loading saliently on the first factor all consist of content relating to Internet or cell-phone use, and was labeled "cyber victimization". Items loading saliently on the second factor all refer to behaviors representing social exclusion and was labeled "relational victimization". Items loading saliently on the third factor represent both verbal and physical victimization, in line with the aforementioned concept of direct victimization [1], [4].

\section{B. Reliability, Descriptive Statistics, and Mean Differences}

Reliability and descriptive statistics for all variables are shown in Table II. Internal consistency was acceptable for all variables, ranging from .74 for cyber victimization to .86 for direct victimization [19]. To compare the relative frequency of the three different types of victimization, total scores for the three victimization scales were calculated as the average rating across all items in the scale. Direct victimization $(M=$ $1.89, \mathrm{SD}=0.79)$ was significantly more frequent than both cyber victimization $(M=1.29, \mathrm{SD}=0.55 ; t=17.645, p<.001$, $\mathrm{d}=0.89)$ and relational victimization $(M=1.55, \mathrm{SD}=0.69 ; t$ $=10.917, p<.001, d=0.46)$. Relational victimization was also significantly more frequent than cyber victimization $(t=$ $8.069, p<.001, d=0.42$ ). 
TABLE I: FACTOR LOADINGS FROM THREE-FACTOR EFA FOR FINAL 23 VICTIMIZATION ITEMS

\begin{tabular}{|c|c|c|c|c|}
\hline & \multicolumn{4}{|c|}{ EFA } \\
\hline & F1 & F2 & F3 & $h^{2}$ \\
\hline Tried to make you fall to the ground by tripping or pushing you & .78 & -.08 & -.09 & .49 \\
\hline Called you by an insulting nickname & .67 & -.05 & .09 & .49 \\
\hline Struck you (e.g., punched, slapped, or kicked you) & .60 & .06 & -.11 & .34 \\
\hline Said they would "get you" later & .60 & .16 & -.16 & .39 \\
\hline Told mean jokes about you & .56 & .02 & .22 & .52 \\
\hline Hid or took your things & .55 & -.03 & .11 & .36 \\
\hline Commented negatively on your weight or size & .53 & -.01 & .10 & .34 \\
\hline Said mean things about you behind your back & .51 & -.01 & .22 & .43 \\
\hline Said something bad about the way you looked & .48 & .11 & .22 & .48 \\
\hline Deliberately knocked books, papers, or other things out of your hands & .46 & .05 & .12 & .31 \\
\hline Threatened you in the hallways between classes & .43 & .28 & .00 & .39 \\
\hline Made fun of you for getting good grades or praise from the teacher & .37 & .07 & .21 & .32 \\
\hline Posted a threatening message about you on the internet & .03 & .94 & -.14 & .84 \\
\hline Posted something humiliating about you on the internet (e.g., MySpace, Facebook etc.) & .02 & .64 & .21 & .57 \\
\hline Made mean comments about your clothes on the internet (e.g., chat rooms, MySpace, Facebook) & .06 & .48 & .14 & .35 \\
\hline Sent you a threatening text message & .06 & .46 & .02 & .26 \\
\hline Refused to sit with you at lunch & -.04 & .28 & .61 & .54 \\
\hline Refused to sit next to you on the bus & -.01 & -.08 & .59 & .32 \\
\hline Ignored you in a group where everyone else was talking & .20 & -.05 & .59 & .50 \\
\hline Not invited you to a party because you were not cool enough & .04 & .09 & .58 & .42 \\
\hline Stopped talking to you, when you used to be friends & .09 & .17 & .54 & .46 \\
\hline Excluded you from a club or activity for no good reason & .04 & .26 & .54 & .50 \\
\hline Excluded you from a chat room or internet forum & .13 & -.04 & .47 & .28 \\
\hline
\end{tabular}

Note. Labels F1, F2, and F3 indicates direct victimization, cyber victimization, and relational victimization respectively. Items loading saliently on a factor $(>.30)$ are bolded.

TABLE II: DESCRIPTIVE STATISTICS FOR ALL VARIABLES FOR WHOLE SAMPLE AND BY GENDER

\begin{tabular}{|c|c|c|c|c|c|c|c|c|c|c|c|c|}
\hline & \multicolumn{5}{|c|}{ Whole Sample } & \multicolumn{3}{|c|}{ Males } & \multicolumn{4}{|c|}{ Females } \\
\hline & \# items & $\alpha$ & $N$ & Mean & SD & $n$ & Mean & SD & $n$ & Mean & SD & $d$ \\
\hline $\begin{array}{l}\text { Direct } \\
\text { Victimization }\end{array}$ & 12 & .86 & 399 & 22.50 & 8.98 & 202 & 22.63 & 10.18 & 184 & 22.90 & 8.84 & -0.03 \\
\hline $\begin{array}{l}\text { Cyber } \\
\text { Victimization }\end{array}$ & 4 & .74 & 399 & 5.10 & 2.00 & 202 & 5.08 & 2.17 & 184 & 5.28 & 2.27 & -0.09 \\
\hline $\begin{array}{l}\text { Relational } \\
\text { Victimization }\end{array}$ & 7 & .81 & 399 & 10.75 & 4.67 & 202 & 10.43 & 4.96 & 184 & 11.41 & 4.80 & $-0.20^{*}$ \\
\hline
\end{tabular}

This result replicates findings by [17] that electronic victimization is less frequently experienced than traditional forms. However, the findings from the current study are in line with recent meta-reviews [2] showing that, on average, most students do not experience victimization (either in school or online).

\section{Gender Differences}

Table 2 also shows the mean scores by gender, as well as the effect size and significance of gender differences. All gender differences were of small effect size. Of the three victimization subscales, only relational victimization showed a significant gender difference, with girls scoring higher than boys, $t(384)=1.974, p=.049$.

\section{DISCUSSION}

\section{A. Factor Structure of Victimization}

The hypothesized distinction between cyber victimization and school-based forms of victimization was supported, suggesting that cyber victimization is qualitatively and psychometrically different from traditional, school-based forms, thereby providing evidence of the measure's construct validity [2], [4]-[6], [10]. However, in this study, physical and verbal victimization items did not form separate factors as they have in previous research [4]. One reason for this may be the use of ninth-grade students as a sample. Research has shown that physical bullying is less common in high school 
students than among younger children [2], [20], [21]. Therefore, it is possible that a different structure (differentiating physical and verbal victimization) would emerge in younger age groups. Nonetheless, the frequency of cyber victimization was substantially different from direct and relational victimization. The prototypical victimization from school-based bullies is still the most common form experienced by adolescents [2], with students experiencing much less cyber victimization. This is not to say cyber bullying is not occurring in schools.

\section{B. Gender Differences in Victimization}

Although there were no significant sex differences in direct or cyber victimization, females experienced a greater degree of relational victimization, consistent with past research [2]. In general though, gender differences were of small effect size, suggesting that all forms of victimization are prevalent for boys and girls.

\section{Implications of Findings}

The three factors revealed during the analysis relate to the forms of victimization most common within our schools. While many bullying measures [1], [2] include items designed to assess the levels of overt and relational forms of bullying, few bullying measures are able to reliably measure electronic bullying. This measure was able to isolate electronic victimization as a separate factor from face-to face relational. In addition, this measure was also able to separate direct bullying from relational and electronic bullying. Unfortunately, the measure was not able to distinguish verbal and physical bullying as two separate factors even though "being made fun of" is clearly different from "being punched". Overall, these results are potentially useful for guiding resource allocation for anti-bullying programs [2], [6], [12]. Specifically, the findings suggest that such programs need to target both boys and girls across all varieties of victimization, focusing not just the victimization that can be seen and heard, but also the behaviors taking place behind closed doors and off school grounds [2], [22]-[24].

\section{Limitations and Future Directions}

Despite simultaneously examining cyber, direct, and relational victimization with multiple items, there are limitations of this study. A main limitation of the current study stems from external validity concerns arising from the utilization of a sample consisting of exclusively ninth-grade students. Many studies [1], [2], [20] have shown that as students get older, incidents of physical bullying decline, while relational bullying becomes more frequent.

Future research, with larger and more robust samples, is needed to determine if victimization is not only qualitatively different at different ages, but also psychometrically different. Finally, the findings from this study also illustrate the utility of using EFA methods to examine the structure of bullying. Given the shortcomings in the current literature on bullying, this study should serve as a call for more researchers to employ EFA methods, along with use of a priori methods (i.e., confirmatory factor analyses), in order to get a more holistic picture of bullying as a construct [2], [10], [25].

\section{CONCLUSION}

The results of this study support the idea that victimization is multidimensional, and that electronic victimization is qualitatively and psychometrically different from direct and relational victimization. Findings from this study are inline with recent research [2], [9] that has found cyber to be a separate construct from school-based victimization. Although physical and verbal items combined to form one factor, relational remained a distinct construct from cyber and direct. Future study is needed to see how the three constructs uncovered in the exploratory factor analysis relate to known correlates of victimization (e.g., GPA, coping ability, depression, and life-satisfaction). Taken together, these findings indicate that school professionals need to "double down" on this issue. That is, strengthen their efforts building and promoting healthy peer relations so that interactions among students are more positive both in school and online.

\section{ACKNOWLEDGMENTS}

The author would like to thank Tanja Bauden, Juana Betancourt, Alpana Bhattacharya, Linnea Ehri, Bruce Homer, Eleanor Horne, Helen Johnson, Mario Antonio Kelly, Anastasiya A. Lipnevich, Carolyn MacCann, Keith Markus, David Rindskopf, Jay Verkuilen, and Richard D. Roberts for supporting the preparation of this manuscript.

\section{REFERENCES}

[1] D. Olweus, "Peer harassment: A critical analysis and some important issues," in J. Juvonen and S. Graham (Eds.), Peer Harassment in School: The Plight of the Vulnerable and Victimized, pp. 3-20, New York: Guilford Press, 2001.

[2] H. J. Thomas, J. P. Connor, and J. G. Scott, "Integrating traditional bullying and cyberbullying: Challenges of definition and measurement in adolescents - A review," Educational Psychology Review, pp. 1-18, 2014.

[3] S. Bauman and A. D. Rio, "Preservice teachers' responses to bullying scenarios: Comparing physical, verbal, and relational bullying," Journal of Educational Psychology, vol. 98, pp. 219-231, 2006.

[4] J. J. Blake, E. S. Kim, A. L. S. McCormick, and D. Heyes, "The dimensionality of social victimization: A preliminary investigation," School Psychology Quarterly, vol. 26, pp. 56-69, 2011.

[5] H. Mynard and S. Joseph, "Development of the multidimensional peer-victimization scale,” Aggressive Behavior, vol. 26, pp. 169-178, 2000 .

[6] C. Hunt, L. Peters, and R. M. Rapee, "Development of a measure of the experience of being bullied in youth," Psychological Assessment, vol. 24, pp. 156-165, 2012.

[7] N. R. Crick, J. K. Grotpeter, and M. A. Bigbee, "Relationally and physically aggressive children's intent attributions and feelings of distress for relational and instrumental peer provocations," Child Development, vol. 73, pp. 1134-1142, 2002.

[8] D. L. Espelage, S. E. Mebane, and S. M. Swearer, "Gender differences in bullying: Moving beyond mean level differences," in D. L. Espelage and S. M. Swearer, Eds., Bullying in American Schools: A Social-Ecological Perspective on Prevention and Intervention, pp. 15-35, Mahwah, NJ: Erlbaum, 2004.

[9] A. G. Dempsey, M. L. Sulkowski, J. Dempsey, and E. A. Storch, "Has cyber techonology produced a new group of peer aggressors?" Cyberpsychology, Behavior, and Social Networking, vol. 14, pp. 297-302, 2011.

[10] E. Menesini and A. Nocentini, "Cyberbullying definition and measurement: Some critical considerations," Journal of Psychology, vol. 217, pp. 230-232, 2009.

[11] E. Menesini, A. Nocentini, and P. Calussi, "The measurement of cyberbullying: Dimensional structure and relative item severity and discrimination," Cyberpsychology, Behavior, and Social Networking, vol. 14, pp. 267-274, 2011.

[12] M. Ybarra, K. Mitchell, J. Wolak, and D. Finkelhor, "Examining characteristics and associated distress related to internet harassment: 
Findings from the second youth internet safety survey," Pediatrics, vol. 118 , pp. 1169-1177, 2006.

[13] M. L. Ybarra, M. Diener-West, and P. J. Leaf, "Examining the overlap in the internet harassment and school bullying," Journal of Adolescent Health, vol. 41, pp. 42-50, 2007.

[14] J. Liu and N. Graves, "Childhood bullying: A review in constructs, concepts, and nursing implication," Public Health Nursing, vol. 28, pp. 556-568, 2011

[15] R. D. Roberts, A. C. Betancourt, J. Burrus, S. Holtzman, N. Libbrecht, C. MacCann, G. Matthews, J. Minsky, B. Naemi, and R. Schulze, Multimedia Assessment of Emotional Abilities: Development and Validation, Army Research Institute Report Series, Arlington, VA: ARI, 2011.

[16] B. Naemi, E. Gonzalez, J. Bertling, A. Betancourt, J. Burrus, P Kyllonen, J. Minsky, P. Lietz, , E. Klieme, S. Vieluf, J. Lee, and R. D. Roberts, "Large-scale group score assessments: Past, present, and future," in D. Saklofske and V. Schwean, Eds., Oxford Handbook of Psychological Assessment of Children and Adolescents, Cambridge, MA: Oxford University Press, 2011.

[17] P. K. Smith, J. Mahdavi, M. Carvalho, S. Fisher, S. Russell, and N. Tippett, "Cyberbullying: Its nature and impact in secondary schoo pupils," Journal of Child Psychology and Psychiatry, vol. 49, pp. 376-385, 2008.

[18] B. P. O'Connor, "SPSS and SAS programs for determining the number of components using parallel analysis and velicer's MAP test," Behavior Research Methods, Instruments, \& Computers, vol. 32, pp. 396-402, 2000.

[19] J. D. Wasserman and B. A. Bracken, "Psychometric characteristics of assessment procedures," in J. R. Graham and J. A. Naglieri, Eds., Handbook of Psychology, pp. 43-66, New York: John Wiley \& Sons, 2003.

[20] K. Rigby and P. K. Smith, "Is school bullying really on the rise?" Social Psychology of Education, vol. 14, pp. 441-455, 2011.
[21] S. K. Schneider, L. O’Donnell, A. Stueve, and R. W. S. Coulter, "Cyberbullying, school bullying, and psychological distress: A regional census of high school students," American Journal of Public Health, vol. 102, pp. 171-177, 2012.

[22] J. Burrus, D. Elliott, M. Brenneman, R. Markle, L. Carney, G. Moore, A. Betancourt, J. Jackson, S. Robbins, P. Kyllonen, and R. D. Roberts, "Putting and keeping students on track: Toward a comprehensive model of college persistence and goal attainment," ETS Research Report RR-13-14, August 2013.

[23] J. Burrus, A. Betancourt, S. Holtzman, J. Minsky, C. MacCann, and R. D. Roberts, "Emotional Intelligence relates to well-being: Evidence from the situational judgment test of emotional management," Applied Psychology: Health and Well-Being, vol. 4, pp. 151-166, 2012.

[24] R. Ortega, P. Elipe, J. A. Mora-Merchán, J. Calmaestra, and E. Vega, "Emotional impact on victims of traditional bullying and cyberbullying: A study of Spanish adolescents," Journal of Psychology, vol. 217, pp. 197-204, 2009

[25] D. A. Kenny. (2014). Measuring model fit. [Online]. Available: http://davidakenny.net/cm/fit.htm.

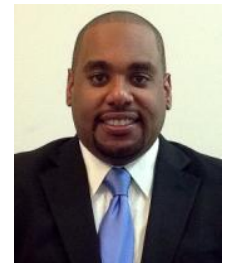

Anthony C. Betancourt is an educational psychology $\mathrm{PhD}$ student at the Graduate Center of the City University of New York. Before becoming a PhD student, he worked as a research assistant at the Educational Testing Service in Princeton, NJ. His work has been published in peer-reviewed journals and books including Applied Psychology: Health and Well Being and the Oxford Handbook of Psychological Assessment of Children and Adolescents. He is a member of the American Educational Research Association, the American Psychological Association, and the Northeastern Educational Research Association. His research interests include bullying, psychometrics, coping, identity, teamwork, leadership, and resilience. 